\title{
How To Use The Pop-Screen In Literary Studies
}

Alexandra Reuber, Tulane University, USA

\begin{abstract}
Teaching literary theory is fascinating for those who love the application of theory to a literary text, difficult for those who are of the opinion that theory destroys the actual beauty and value of the fictional source, and unfortunately often boring for those who are taught. This article, however, provides a popular approach to the introduction to classical Freudian literary criticism by choosing David Koepp's cinematographic adaptation of Stephen King's novella Secret Window. David Koepp's film Secret Window (2004) is a valuable teaching tool, as it invites the viewer to observe Mort Rainey's - the film's main character-psychologically unstable mind and emotional distress processed in his dream states, hallucinations, and anxiety attacks. Moreover, the film illustrates well the Freudian concept of repression, of the uncanny, of dream work, and of the interplay of the three psychological entities-ego, Id, super-ego. This differentiated introduction to important Freudian concepts and his understanding of dream-analysis is student centered, motivating, interactive, and helps students to develop their critical and media literacy.
\end{abstract}

Keywords: Psychoanalytic theory, Sigmund Freud, dream analysis, the uncanny, ego, Id, super-ego, double figure, development of critical and media literacy, Stephen King, multimodal communication

\section{INTRODUCTION}

$\mathscr{J}$ eaching literary theory is fascinating for those who love the application of theory to a literary text, difficult for those who are of the opinion that theory destroys the actual beauty and value of the fictional source, and unfortunately often boring for those who are taught. In the following, I show how to inspire students in a special topic seminar on Gothic Fiction for "the inevitable component" of literary studies by introducing psychoanalytic literary criticism via popular culture elements such as pictures, text and film excerpts. The seminar's general topic offers the perfect literary environment for classical psychoanalytic criticism, as Gothic fiction appeals to our secret wishes, repressed desires, and hidden anxieties and fears respectively. As Elizabeth MacAndrew (1979, p. 3) states in her valuable theoretical elaboration of the Gothic, it is "a literature of nightmare" that shows "dream landscapes and figures of the subconscious imagination" and as such explores "the mind of man."

In the course of five seventy-five minute class periods, teachers using this approach can discuss important Freudian concepts expressed in On Dreams (1901) and in Freud's essay The Uncanny (1919) using text excerpts taken from Stephen King's novella Secret Window, Secret Garden (1990) and David Koepp's 2004 cinematographic adaptation of the same. Teachers can then put theory into practice via pre-, while-, and post-reading activities that can be applied to any other psychological thriller serving as a teaching tool for psychoanalytic criticism in any literature seminar.

I propose this popular culture oriented introduction to psychoanalytic theory for different reasons: First, even though it is relatively easy to excite students for the discussion of a Stephen King masterpiece in a literature seminar, it is difficult to do the same with theoretical texts written by Sigmund Freud. Whereas Freud is out, King is in, not only because he is risky, frightening, and graphic, but also because, as Victor Sage states, "the textual psyche he constructs is one which in some sense 'matches' the cultural psyche of the late twentieth century in the West" (1996, p. 125). In addition to the contextual appeal, King's stories are "much more accessible and inviting than most of the works [students] are required to read in the classroom" (Skretta, 1997, p. 135), especially literary theory.

Second, the use of popular culture components appeals to the students' visual orientation and their 
"immediate interest in and uncanny ability with film" (Golden, 2001, p. xiii). As such, this approach enhances critical and media literacy, since the analysis of film excerpts and the decoding of the visual image improve students' analytical and reading skills they eventually will apply to the written text. The students' interaction with different meaning-making systems as for example the oral, auditory, visual, and textual, thus complements conventional text analysis and results in a "multimodal communication" (Albers, 2007, p.11).

Third, film is a very useful medium to introduce students to a psychoanalytical approach to fiction in general, and to Freudian dream analysis in particular, since a film, similar to a dream, a hallucination, or a déjà vu experience "places the viewer in a paradoxical position between poles of distance and proximity, and absence and presence" (Weaver, 2005, p. 51). The viewer, like the dreamer, is withdrawn from reality when fully absorbed in the story. Both are confronted with what Vicky Lebeau (2001, p. 35) defines as "a world apart;" a world that unconsciously portrays psychoanalytical concepts. Similar to a dream, films have to be understood as a narrative in images showing a pictographic language constructed of symbols, metaphors, distortions, and composite figures that function as mirror images of "something hidden in our subconscious" (Weaver, 2005, p. 53). Both film and dream are something other, "a full-scale simulation of the perceptual world" (Revonsuo, 2005, p. 205) that offers a multitude of interpretations due to its condensed and distorted representation of reality.

In our case, David Koepp's film Secret Window (2004) presents the dichotomous positions of absence and presence, the real and the surreal, the world that surrounds us and the dark world that is part of us-the unconscious - through the main character's reoccurring flashbacks, hallucinations, and fugues into the dream world. The film invites the viewer to observe Mort Rainey's — the film's main character-psychologically instable mind that is haunted by the distorted, condensed, and repressed love for his ex-wife and his incapability to write. Via the depiction of Mort Rainey's emotional distress processed in his dream states, hallucinations, and anxiety attacks, the film illustrates well the Freudian concept of repression, of the uncanny, and of dream work. The fact that the film also visualizes the interplay of the three psychological entities - ego, Id, super-ego-makes it a valuable teaching tool for this unit.

Using this film in combination with supporting text material enriches the student's exposure to fiction (film and text) and creates a learning environment that will teach students an active reading of both text and film. This approach will move them "from uncritical acceptance of [popular culture] to not only [a deeper] awareness" (Foertsch, 2006, p. 212), but more so to the understanding of psychological concepts and their representation in and application to (popular) fiction. It will enhance their critical literacy.

\section{Part One: Setting a Psychoanalytical Framework}

This first class unit starts with the viewing of the first two film scenes (00:00:25-00:08:08), which introduce the students to the film's setting and characters-Mort Rainey, John Shooter, Amy Rainey, and Ted Milner-, provides them with the main conflict and essential background information for plot development, and foreshadows the diverse set of problems Mort Rainey will face and process. From my own experience I can confirm that when students are asked to watch a film segment, everybody is interested and pays attention, especially when it is an adaptation of a Stephen King text. At this point however, I want to attest that this unit desires neither to entertain nor to replace (what is considered) standard conventional class time with "fun movie time." In the present case, the use of Secret Window has a clear goal in mind: the teaching of psychoanalytic literary theory.

In contrast to the other three in-class screenings, this brief introductory screening is not accompanied by any while-viewing activity, since its sole purpose is to provide the foundation of the unit's psychological framework. The showing is, however, followed by a group discussion, in which the following points should be addressed: a) the relationship between Mort Rainey and his soon-to-be ex-wife, b) the relationship between Mort Rainey and John Shooter, c) the setting, and d) Mort Rainey's possible state of mind. As these four points are major constituents of the first two scenes, it is very likely that the students will elaborate on these issues without the teacher's guidance or interference. In case the students do not express any opinion or assumption on Mort Rainey's state of mind, the teacher should pose questions such as: "How would you characterize Mort Rainey?" or "How does the film present Mort Rainey?" Both of these questions have the same goal, namely the physical, emotional, and psychological characterization of Mort Rainey via the first two scenes. I advise that the teacher lists the student 
comments on the board (see Chart 1), as these will be useful when analyzing the second visual element, the DVD cover (see Illustration 1).

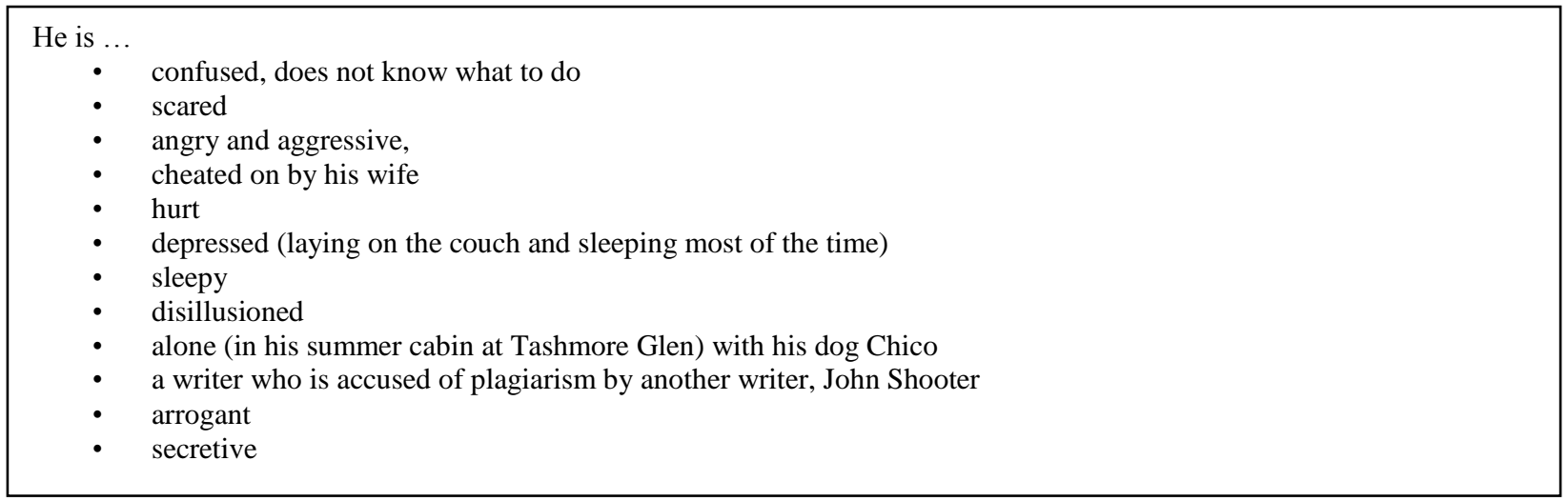

Chart 1: Board Comments - How would you Characterize Mort Rainey?

After letting the students express their assumptions about Mort Rainey's emotional and psychological well being, the teacher shows the DVD cover presenting an extreme close-up shot of Johnny Depp, alias Mort Rainey, and asks the students to reflect upon how their comments find expression in this DVD cover (Illustration 1).

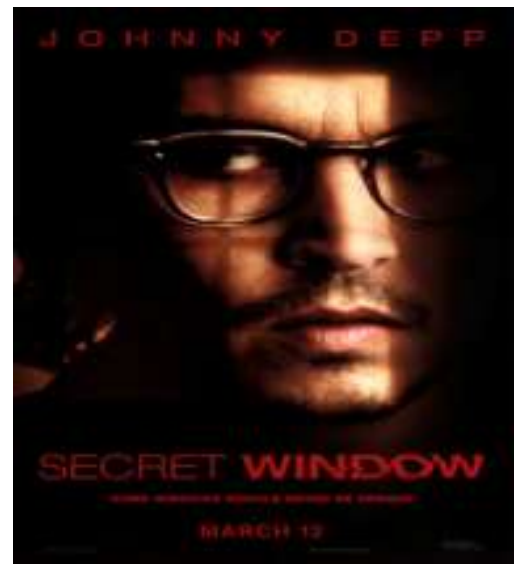

Illustration 1: DVD cover - Extreme Close-up Shot of Johnny Depp

In order to give every student the possibility to express his / her opinion, this second warm-up exercise should be done first via free writing. This individual "reading" of the picture should then be complemented by a ten minute presentation and open discussion of the student's associations, which forces them "to communicate their findings [expectations, and predictions] in a variety of ways, to themselves and others" (Haworth, 2004, p. 69); an activity that fosters their independent thinking and self-confidence to present their opinions. Since this unit is part of a special topic seminar on Gothic fiction, the teacher can be assured that the students will share initial comments regarding the DVD cover, and previously acquired knowledge about Gothic fiction ${ }^{1}$ in communication with each other. They will allude to typical motives such as gothic villain, solitary setting, mental instability, persecution of the innocent, etc. Furthermore, they will expand on colors, shapes, lighting, and the picture's symbolic content ranging from the symbolic reading of the main character to the symbolic reading of the colors. When elaborating on the symbolic reading of the main character, it is likely that students illustrate that a large portion of Johnny Depp's face is concealed in the dark, which is strongly supported by the dominating black surrounding. Students will point out that the face being only half lit lets the character appear reflective, occupied, hurt, immobile, and passive. In this 
respect, they may even elaborate on the cinematographer's choice of both hard lighting and natural lighting, as well as the choice of extreme close-up shot putting the character at the center of the viewer's attention. Very engaged students might even read this extreme close-up shot as an eye-level shot creating the illusion that first, we stand right in front of the character, second, the subject might address us, the viewer, and third, that we are somehow involved in the questions why "some windows should never be opened" (DVD cover). In regard to the symbolic reading of the colors, students will understand black as the color of death, secrecy, evil, and of the unknown; red as the color of love, sexuality, passion, heat, and anger; and white ${ }^{2}$ as the color representing morality and purity.

In general, we can assume that this combined introduction of film sequence and DVD cover to text- and film analysis helps to build up expectations of what a modern Gothic text / film of the twentieth century is about and reinforces the usage of the language of film that students will (most likely) have learned ${ }^{3}$ while analyzing for example Kenneth Branagh's 1994 adaptation of Mary Shelley's Frankenstein, Francis Ford Coppola's 1992 interpretation of Bram Stoker's Dracula, or Alejandro Amenábar's 2001 "ghost movie" The Others, to name only a few. At the same time, it gives the teacher the opportunity to introduce the Freudian concept of the human mind and the new psychoanalytic vocabulary that is associated with it (Chart 2).

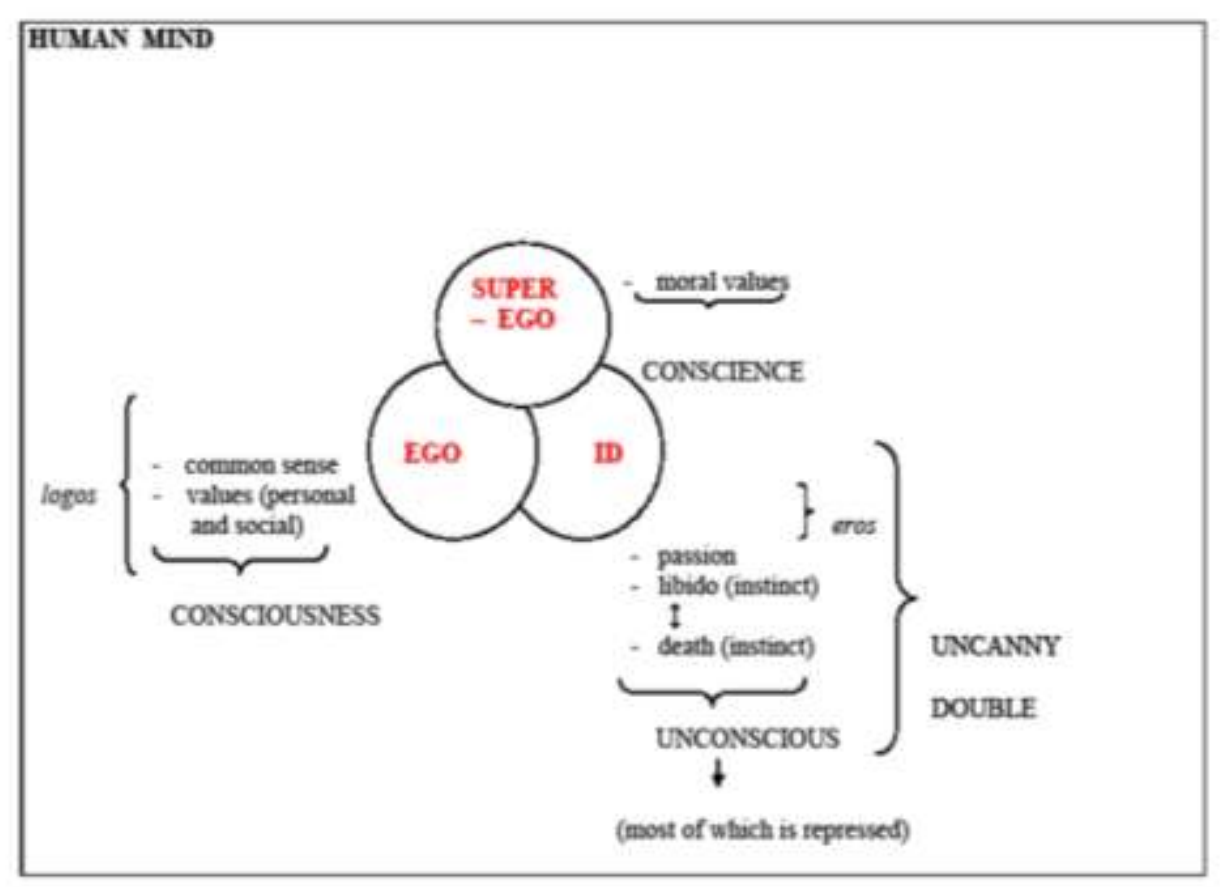

Chart 2: Freudian Concept of the Human Mind

The teacher outlines Sigmund Freud's understanding of the ego, the super-ego, and the Id. (S)he explains that the super-ego represents moral values as well as the "ego ideal," the unconscious identification with or longing for a higher being; that the ego stands for the external world and "what may be called reason and common sense" (Freud, 1923, p. 19); and that the Id encompasses "the internal world" (Freud, 1923, p. 32) containing instincts and passions as well as "the most powerful impulses" (Freud, 1923, p. 32), drives, and anxieties. As such it has to be understood as an opposing entity to the ego and super-ego. To advance the students' understanding of the different concepts and their relation to fiction, it is important that after providing the theoretical outline of the human mind the teacher elucidates how these psychological entities are represented artistically in the picture of Mort Rainey (Chart 3).

- eyes: understood as the door to the soul and psyche

BUT: one eye is covered by a shadow $\rightarrow$ Id overpowering the ego

- white in the eye: represents purity, morality, and his conscience $\rightarrow$ super-ego

- window: symbolizes a glimpse into his psyche, an entrance into a different world

- window bars: suggest entrance to as well as exclusion from something represents repression $\rightarrow$ ego 


\section{Chart 3: Freudian Entities and Popular Fiction}

To further deepen the understanding of the Freudian perception of the human psyche, the teacher should then divide the class into four groups and distribute photocopies of the most important excerpts of Freud's famous essay The Uncanny (1919) to the students (pp. 368-73; 375-378; 385-389; 396-99). Each student reads a total of three to four pages. After five to ten minutes of silent reading, students first inform their peers about the content of their text passages and then exchange ideas about how to understand the Freudian notion of the uncanny and its most important characteristics: the reoccurrence of the repressed as something unfamiliar and unrecognizable, the animation of unanimated matter, the figure of the double, the evil eye, as well as the loss of "one's eyes" (Freud, 1919 , p. 383) in relation to the castration complex; all leading to the most frightening sensation, terror.

In a following third discussion of the picture, students then apply these notions to the DVD cover. The third reading complements the first and second at the same time that it demonstrates that the surrounding darkness is a representation of Mort Rainey's passions and drives, and of his unknown dark half: something that Sigmund Freud calls the double and defines as a figure that is "to be considered identical by reason of looking alike," a figure that "possesses knowledge, feeling and experience in common with another person" (1919, pp. 386; 387). Students might further point out that the figure of the double-as the reoccurring repressed half-provokes Mort's questioning of identity leading to his self-alienation on the one hand, and to the recall of the past that "ought to have remained hidden, but yet comes to light" (Freud, 1919, p. 376), on the other.

This recall of the past and the return of the repressed in relation to the figure of the double is a dominant feature of the film, indicated already by John Shooter's first threatening appearance accusing Mort Rainey of plagiarism in scene 2. Throughout the film, John Shooter functions as the reappearing personification of Mort Rainey's repressed past, a past that goes beyond surprising his ex-wife Amy and her lover Ted in bed on that one cold winter night. It is the familiar notion of betrayal and the fear of self dissolution that comes with it and which haunts the writer. It is "something long known to [him], once very familiar" (Freud, 1919, p. 370) but at the same time, something unfamiliar (unheimlich), something that "has been estranged only by the process of repression (Freud, 1919, p. 394). It is something that "undoubtedly belongs to all that is terrible - to all that arouses dread and horror" (Freud, 1919, pp. 370; 368).

It is something that does not let go of Mort Rainey and that lets his once familiar but repressed love reappear in the form of an (un)familiar but strong desire for as well as fear of fulfilling John Shooter's request "to fix the ending" of his story. It is something that is symbolically expressed in King's textual dream sequences and visualized in the scenes 25, 26 and 27 of David Koepp's film. In this respect we can argue that his wife has triggered something else: Mort Rainey's recollection of his own disloyalty towards one of his fellow writers, hinted at by John Shooter's frequently repeated statement, "You stole my story" (00:04:52). Thus, we can conclude that Amy's actions and behavior have generated the return of Mort's repressed past that now reappears in an unfamiliar disguise: John Shooter, Mort Rainey's dark half.

Even though the film excerpts to be discussed throughout the unit do not directly visualize Mort Rainey 
suffering from fear of castration or from losing his physical eye sight, both of these concepts should find discussion in class for two reasons: First, they are both important characteristics of the uncanny. Second, Mort Rainey feels deprived of his manhood by having lost his wife to another man. The first two film scenes illustrate very well that Mort Rainey is terrified by this sort of castration, which triggers - and is connected to - his extreme anxiety of "going blind" (Freud, 1919, p. 383), meaning here, his fear of losing touch with reality, of going insane; a psychological development which is already indicated in the first two film scenes, a phenomenon that is closely linked to John Shooter's appearance.

Although Sigmund Freud states in his essay "The Uncanny" that "intellectual uncertainty has nothing to do with this effect" (1919, p. 382) of the uncanny, it cannot be denied that this phenomenon plays a crucial role when defining possible sources of the uncanny in film, text, and dream analysis. Whenever the "reading process" is fueled by uncertainty, the "distinction between imagination and reality" (Freud, 1919, p. 398) effaces, and the familiar is represented in an unfamiliar way. When the familiar becomes unfamiliar, hesitation is provoked and rationality and logic are challenged. It is then that the uncanny becomes an expression of crisis, as is shown throughout the film.

A desired closure of this first of the five seventy-five minute class periods would be the teacher's summary of the learned material including the remark that our hidden personality-our dark half—in general, and our illegitimate desires and longings in particular, often find expressions in dreams and hallucinations; mental processes that Sigmund Freud ascribes to the $I d$, the entity "which contains the passions" (1923, p. 19) and which we associate with the unconscious that is partly repressed. The instructor's brief reference to the highly condensed, contracted, distorted, composite, and symbolic language of a dream from which we have to "disentangle its meaning" (Freud, 1900 , p. 311) is important as it serves as a transition to the next class period which will focus on the reading and understanding of dreams.

\section{Homework: Reading of selected passages of Sigmund Freud's On Dreams (1901)}

\section{Part Two: Creating and Reading Dreams}

At the beginning of this second seventy-five minute session, the entire class discusses assigned readings taken from Freud's On Dreams ${ }^{4}$ (pp. 8-54). Students learn that consistent with Freud's dream analysis, a dream can be subdivided into the dream thought and dream content. The understanding of the two categories is important, since dream thoughts are defined as being "immediately comprehensible, as soon as we have become aware of them," (Freud, 1900, p. 277) whereas their dream content, due to its pictographic language, is not. Similar to any fictional text or film, dream thoughts - according to Freud - convey the obvious meaning of the dream, whereas the dream content focuses on the discovery and explanation of "hidden fields" within the dream thoughts. As a result, students learn that in order to understand a dream fully, they first have to analyze its language and see what it obviously conveys. Then, they have to work on its still hidden content, the unknown or unconscious part; a process that involves a confrontation with the known (the obvious meaning) and the unknown (the hidden message) implying the encoding of the dream's symbolic language, which is complicated by the ego's attempt of censorship manifesting itself in phenomena such as condensation, contraction, displacement, disfiguration, and often regression (Chart 4). Students learn that similar to any reading of a text or film, they have to read between the lines when analyzing a dream sequence.

Like most literature-based films, Secret Window falls into the category of traditional film translation implying that the director adheres "to the overall narrative characteristics of the literature" (Cahir, 2006, p. 37), but takes the freedom to alter the literary source by editing the text, modifying the setting, or using composite structures and characters. Even though David Koepp's realization is very close "to the original literary text" (Cahir, 2006, p. $21)^{5}$, and the director shows on at least six occasions ${ }^{6}$ Mort Rainey's attempt to escape from his painful and solitary life through sleep and the field of dreams, the two explicit and well-defined dream sequences that are present in King's short story have only been implicitly translated and incorporated into the film's main plot. On the one hand, this modification allows "for greater freedom in rendering meaning" (Cahir, 2006, p.22) to the entire film. On the other hand it complicates the viewer's entrance into Mort's disturbed mind. 


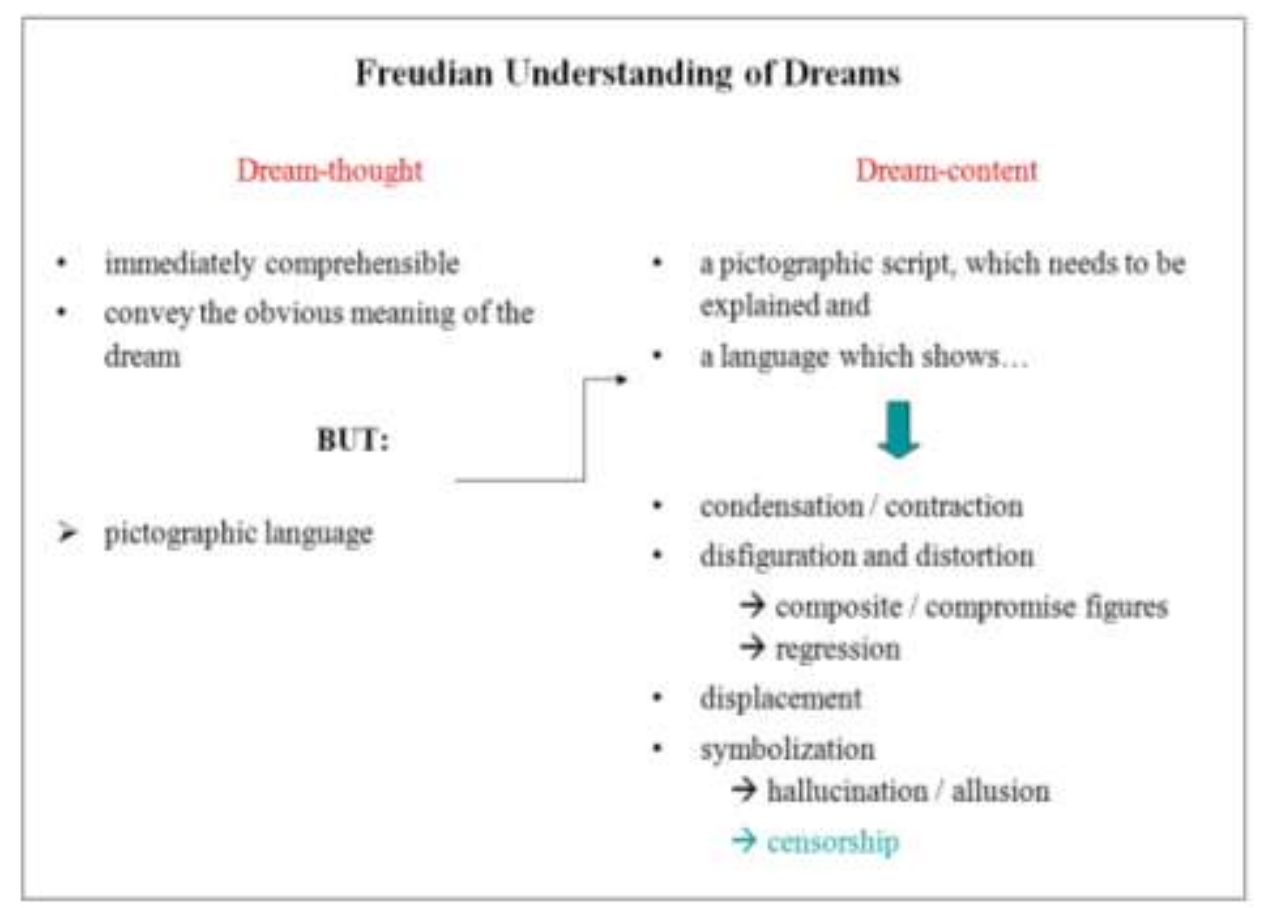

Chart 4: Freudian Understanding of Dreams

Hence, when using Secret Window as a tool to teach the Freudian concept of the human psyche and his understanding of dream analysis, it is meaningful to work only with a few selected film scenes ${ }^{7}$ and to complement the visual with the textual source. As we will see, the combination of text and film excerpts is an excellent means to obtain a complete understanding of Mort's inner and outer life, and to address and comprehend Freudian key concepts of dream analysis - as for example the phenomena of displacement, symbolization, condensation, and distortion - from a textual and visual point of view. The critical analysis of these dreams - holding the information about Mort Rainey's true self-are the main focus of the third lesson, in which the analysis of the short-story's explicit dream sequences and their cinematographic adaptation is the center of interest.

For the remaining time of this lesson, I propose the following creative application of the theoretical material discussed: Together with a partner, students write one character journal entry, in which they take over Mort Rainey's persona and outline two dreams that may have occurred after Mort Rainey's discovery of his wife's disloyalty and after the initial conversation with John Shooter. This assignment allows students to express their understanding of the fictional and non-fictional source "in their own words through the point of view of one [in our case of the main] character" (McKnight, 2008, p. 139), and to elaborate for example on his social position, unique self-contempt, emotional imbalance, dependence on his ex-wife Amy, his irrational anxieties, hallucinations, and mood swings.

This role-play furthers the students' understanding of Freud's theoretical elaboration on dreams and their future engagement with the text and his main character, as it fortifies their awareness of the highly condensed and distorted dream language that lets manifest dream thought differ from its latent content. Moreover, it shows them the interconnectedness of fictional and non-fictional material and prepares them for the actual forthcoming interpretation of the three dreams: "Mort and Amy," "Meeting Shooter and Amy in the cornfield" and "The classroom of the School of Hard Knocks." An open discussion of the presented journal entries should end this second lesson on Secret Window. No homework assigned. 


\section{Part Three: Captured in the Field of Dreams}

In this third class, students will work with two texts and two film excerpts. The combination of both fictional sources is essential as it exemplifies the film's traditional translation of Stephen King's text, helps the less active reader to access easily the text's content via the film's visual nature, challenges the more active reader to unfold the text's symbolic content through film analysis, "[keeps] the audience's attention" (Golden, 2001, p. 36), and illustrates that a psychoanalytical reading can be applied to each fictional source, respectively. The examination starts with the very self-explanatory dream reference (Chart 5):

Mort and Amy

"He dreamed of Amy. He slept a great lot and dreamed of Amy a great lot these days, and waking up to the sound of his own hoarse shouts no longer surprised him much" (King 1991: 246).

\section{Chart 5: Dream Reference to Dream 1}

Even though this text excerpt is not "an actual dreamed dream [...] but a public representation of it in outer speech" (Easthope, 1999, p. 11), it needs to be included in this psychoanalytical approach to text and film, as it expresses Mort's state of mind, which is haunted by separation anxiety, nostalgia, and emotional distress. Moreover it is a representative example for the category of dreams "without any displacement" (Freud, 1901, p.34). It is a meaningful and self-explanatory dream, which does not show any distortion and which "can be inserted without further difficulty into the context of [Mort's] mental life" (Freud 1901, p.18); a life without his wife; a life that is characterized by maladaptive coping with reality.

After a brief evaluation of the dream reference, the teacher should present David Koepp's radical translation of the dream sequence, scene eight (0:21:35-0:25:50). In order to analyze the film excerpt in detail, it is important to ask the class to take notes on several dichotomous motifs associated with the scene's theatrical and literary elements, as well as its cinematic effects such as lighting, colour, angles, shots etc. To guarantee "a high level of engagement with [the] film" (Golden, 2007, p. 25), I recommend distributing a handout including the points of interest (Chart 6) prior to the screening of scenes eight and nine.

\begin{tabular}{|l|l|l|}
\hline SCENE 8 and 9 & Examples from the Scenes & Explanation of the Dichotomous Examples \\
\hline setting (inside vs. outside) & & \\
\hline Mort (acting and behaviour) & & \\
\hline shots and angles of Mort & & \\
(long shot vs. Medium shot) & & \\
(long shot vs. Close-up or extreme close-up & & \\
shot) & & \\
(low vs. bird's eye-view) & & \\
\hline $\begin{array}{l}\text { Shots and angles of the dog } \\
\text { (long shot vs. Medium shot) } \\
\text { (long shot vs. Close-up or vs. Extreme close- }\end{array}$ & & \\
up shot) & & \\
\hline lighting (dark vs. light) & & \\
\hline
\end{tabular}

Chart 6: Points of Interest for Scenes 8 and 9

After the viewing, the students should take a few minutes to complete the handout, and then reveal their first impressions and individual understanding of the film sequence. In order to indirectly guide the students' reading of the motion picture, the teacher should list and organize students' comments in a mind-map (see Chart 7) on the board. By doing so, the teacher puts text, film, and students in communication with each other and, consequently, allows the students not only to analyze Mort's dream, but also to create the hidden subtext of the fictional source. As a consequence, students function as what Wolfgang Iser once called "the artistic pole" in a relationship that is 
defined by the interaction between text/film and reader/viewer. Only when remarks or observations need further explanation, should the teacher enter the "reading process" of the film. The teacher's reticence guarantees the students" development of "judgements toward arts" (Albers, 2007, p. 11) and leads to an improvement of their analytical abilities.

It is, however, important that students recognize and discuss all important features causing the dream's "bewildering effect" (Freud, 1901, p. 19) such as condensation, symbolic imagery, and displacement. To understand the dream work and its "disconnected fragments of visual images" (Freud, 1901, p.40), we always have to include the impressions of the past few weeks, days, and especially those "immediately preceding the dream" (Freud, 1901, p.35).

The house (inside and outside), the dog (close and far away), and Mort's behaviour (passive and active) are all constituents of Mort's symbolic and displaced fall down the cliff into the raging sea, both dream thoughts containing key-information about Mort's emotional state. It is critical that the students understand the dream's condensed and highly symbolic imagery and its relatedness to Mort's waking life, in which he seems to be drowning. The waves of Mort's new solitary life are cold and forceful. They pull him down into the dark ocean of depression, making him reliving the past over and over again, until he suffers from complete dysfunction, selfcontempt, and self-alienation. As the film beautifully visualizes, for Mort Rainey the glass is always half empty but never half full. Chart 7 shows possible comments and their visual arrangement on the board, opposing Mort Rainey's dream life and reality.

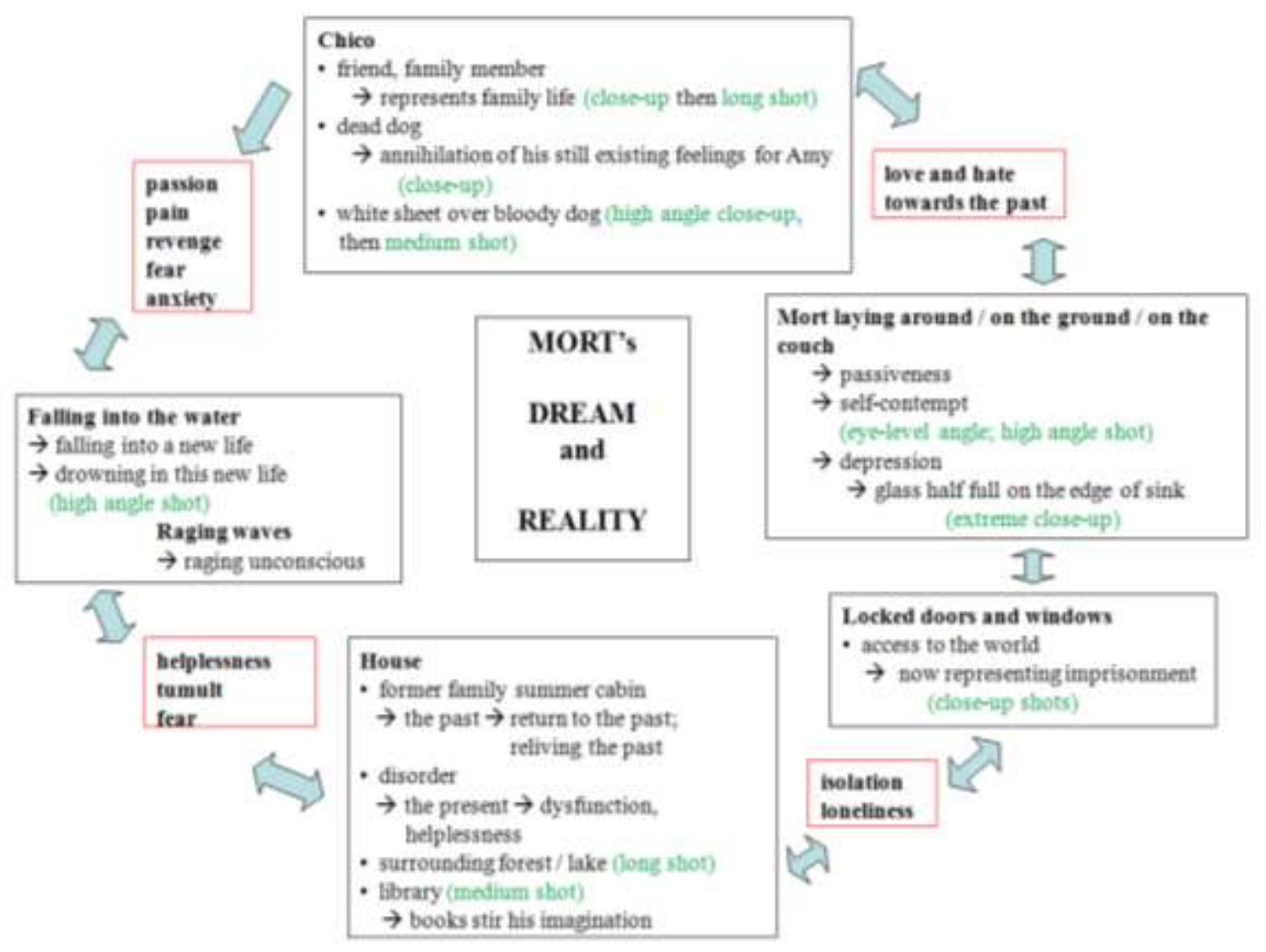

Chart 7: Possible Student Comments - Mort's Dream and Reality 
After discussing the film section, students will be able to conclude that Mort Rainey is mainly ruled by his past, leading to strong anxiety attacks and the fear of self-dissolution. These emotional states find expression in the mise-en-scène as well as in the frequent close-up shots, which facilitate the illustration of Mort's inner turmoil, which too often cannot be adequately expressed by words. Students will understand that the man's emotional distress has become a life-threatening sensation. In Chart 8, this realization leads to the examination of the second dream, entitled "Meeting Shooter and Amy in the cornfield."

Meeting Shooter and Amy in the Cornfield

He dreamed he was lost in a vast cornfield. He blundered from one row to the next, and the sun glinted off the watches he was wearing — half a dozen on each forearm, and each watch set to a different time.

Please help me! He cried. Someone please help me! I'm lost and afraid!

Ahead of him, the corn on both sides of the row shook and rustled. Amy stepped out from one side. John Shooter stepped out from the other. Both of them held knives. I am confident that I can take care of this business, Shooter said as they advanced on him with their knives raised. I am sure that, in time, your death will be a mystery even to us. Mort turned to run, but a handAmy's, he was sure - seized him by the belt and pulled him back. And then the knives, glittering in the hot sun of this huge secret garden- $-($ King 1991, p. 255)

Chart 8: Representation of Dream 2

A good reader should read the short text aloud, since the theatrical delivery of the text heightens listeners' curiosity, sharpens their observation, enhances their listening skills, develops their "imaginative engagement and involvement" (Haworth, 2004, p. 68) with the text, and conveys the emotional stress this dream imposes on the dreamer.

A brief phase of free writing should follow the reading, as it allows each student to deconstruct the dream, to interpret its symbolic and condensed language, and to function as a reflective and critical thinker. The individual results should then be presented to and evaluated by the entire group, who then analyzes the dream in its entirety and reviews its importance for plot and character development. Results should be organized in another mind-map, which this time, however, should be created by the class. In doing so, every student is involved in the discussion, contributes to the symbolic and psychoanalytical understanding of the text, and expands his/her skills of critical thinking from a multisided perspective.

At this point, the students will be proficient enough to comprehend the dream's disguised, censored, and displaced representation of images. They will be able to point out that the dream's first two sentences reveal "a transference and displacement of [Mort's] psychical intensities" (Freud, 1900, p. 343), namely his unsuccessful process of his wife's disloyalty and the resultant divorce. Moreover, they will comprehend that the half dozen watches on Mort's arm and his blundering through the rows of the "vast cornfield" are dream ideas appearing "in an apparently trivial or marginal form" (Easthope, 1999, p. 11) suggesting, however, Mort's mental imbalance, helplessness, and confusion. It is in this "vast cornfield" and "huge secret garden" -both condensed images of fruitful soil and secrecy - that Mort plants the seeds of love and hate, of loyalty and disloyalty, of safety and threat, as well as of the past opposing the present.

This dream exemplifies that Mort's complex inner conflict has undergone a serious "amount of compression" (Freud, 1900, p. 313) taking here the form of the condensed picture of the "secret garden," synonymously referred to as "vast cornfield" that is heated by the "hot sun." In relation to the human psyche, the "vast cornfield" has to be understood as an allegorical representation of the labyrinthine unconscious, the home of the unfamiliar John Shooter on the one hand, and of Mort's feelings for his all too familiar ex-wife Amy, on the other. The dream thought of the ocean has here been displaced by the "vast cornfield." Even though the dream imagery has changed, the dreams are connected by the displaced and condensed dream thoughts of the dark ocean and the vast cornfield, since both represent Mort's unconscious in which he is helplessly lost. The resulting 
emotional, psychological, and physical threat finds illustration in several other dream thoughts: the shaking row of corn, John Shooter, Amy, the belt, and the raised knives.

Whereas some students will understand Amy's threatening appearance with another man as an allusion to Mort's discovery of her betrayal and the resulting annihilation of the once established marital, personal, and emotional life, others might read Amy's combined emergence with John Shooter as a menace to Mort's professional life. They may even understand Amy and Shooter as a composite figure of Mort's unconscious desire to react violently against his ex-wife and, thus, read this dream "as a sort of substitute for [Mort's] thought processes, full of meaning and emotion" (Freud, 1901, p. 15), full of the desire of wish fulfilment. In this sense, some students will understand the knife as a dream symbol representing the idea of separation, whereas others might read the knife in a sexual Freudian way, namely as a threatening phallus symbolizing Mort's loss of manhood to another man. Both readings, however, lead to the same outcome: the loss of something very valuable and the pain that is attached to this loss.

Via the intensive analysis of this text excerpt, students study the phenomena of dream condensation, compression, displacement, distortion, and symbolization. Moreover, they learn that this dream has to be seen as an expression of wish fulfilment, since first of all, dreams are always egoistical and second, "the distressing content serves only to disguise something that is wished for" (Freud, 1900, p. 53): Mort's elimination of pain and betrayal. As such, the dream represents "two contrary ideas by the same composite structure" (Freud, 1901, p. 31): Mort Rainey's fear of annihilation on the one hand, and his unrecognizable and disguised wishful thinking to kill her, on the other; an act that is "not visible in the dream itself" (Freud, 1901, p.13), but that corresponds to John Shooter's desired and Mort's almost achieved end of the story. From this follows that Mort's "hallucinatory reproduction of the mental image" (Lebeau, 2001, p. 38) of John Shooter in his waking state is the result of "a work of compression or condensation on a larger scale" (Freud, 1901, p. 27), since Shooter becomes a means of liberation from the past in general, and from the pain and sense of betrayal, in particular. Nevertheless, Mort's hallucinatory perception has a very frightening effect on him in his waking life: paranoia and hysteria.

Within the remaining fifteen to twenty minutes of the seminar, the class should first watch scene twentyone (01:01:28 - 01:05:42), then elaborate on how the second dream has been incorporated into the film. Prior to the screening, the teacher should hand out or project the following two questions on an overhead:

1. How does Stephen King's metaphoric language and David Koepp's use of cinematic effects (close-shots, long-shots, high and low angle, eye level angle, focus) express Mort's emotional stress as well as loss of control?

2. How does David Koepp's alteration of King's textual source affect the "reading" experience of the scene?

This third class ends with a group discussion of these two questions. Students will voice their opinion on David Koepp's alteration of the original source, and his effective alternation between extreme close-up, bird's-eye, long, high, and low angle shots. It is important that students realize that even though Koepp displaced the cornfield and huge garden by a scene in the woods, substituted Shooter's threatening emergence from the cornfield by his dominating presence when Mort awakes after having slept for three hours, exchanged Shooter's and Amy's threatening knives for a bloody axe, and translated Mort's helpless blundering from one row of the cornfield to the next by his first unsuccessfully attempted escape from Shooter in the woods, then by his aggressive outbreak when facing the fork in the road, Koepp visualizes Mort's immense imbalance and anxiety very well! Moreover, the frequent alternation of extreme close-up and rotating bird's-eye shots indicates Mort's psychological occupation with himself, his confusion, his helplessness, and his insignificance. The director's choice of a long low-angle shot of John Shooter standing over the fainted Mort Rainey hints at a similar reading, namely the dominance of Shooter over Rainey, of Id over ego, of double over self. Thus, this scene illustrates a change of command, as well as an increase in Mort's fear of annihilation; an emotion that finds a better illustration in the film than in the original text.

By combining text and film excerpts (Chart 9), students learn how to "read" the textual as well as the cinematographic representation of Mort's symbolic dream language; a practice that reinforces the student's understanding of the different components of Freudian dream analysis and of the interconnectedness of fictional and non-fictional material. It is through the combination of text and film excerpts that we facilitate and support the 
student's understanding of the psychological concepts (to be) discussed and that we also asses the student's knowledge of how to apply psychoanalytic criticism to a fictional source.

Homework: Analysis of Dream 3

Part Four: Composite Structures

The classroom of the "SCHOOL OF HARD KNOCKS"

It was a familiar classroom, although he couldn't have said just why. He was in the classroom with John Shooter. Shooter was holding a grocery bag in the curve of one arm. He took an orange out of the bag and bounced it reflectively up and down in his hand. He was looking in Mort's direction but not at Mort; his gaze seemed fixed on something beyond Mort's shoulder. [...] The writing on the blackboard was [easy] to read. SOWING SEASON A Short Story by Morton Rainey, it said. Suddenly something whizzed over Mort's shoulder, just missing his head. The orange. As Mort cringed back, the orange struck the blackboard, burst open with a rotten squashing sound, and splattered gore across what had been written there. [...] Shooter dipped into his bag again. What's the matter? Shooter asked in his calm, stern voice. Don't you recognize blood oranges when you see them? What kind of writer are you? He threw another one. It splattered crimson across Mort's name and began to drip slowly down the wall. No more! Mort screamed, but Shooter dipped slowly, implacably, into the bag again. [...]; blood began to sweat its way onto the orange's skin in pinprick droplets. No more! No more! Please! No more! I admit it, I'll admit anything, everything, if you just stop. (King, 1991, pp. 275-76).

\section{Chart 9: Representation of Dream 3}

At the beginning of this lesson, students should present their individual analysis of the third dream. We can presuppose that students comment on the life threatening components, which are included in the manifest dream thought as well as in its latent content. This time, however, it is not Shooter's fast moves in a cornfield that trouble Mort's sleep, but his looks, words, and unpredictability of when he throws the next orange against the blackboard of this (un)familiar classroom which increases Mort's nocturnal anxiety and lets him scream: "No more! No more! Please! No more! I'll admit it, I'll admit anything, everything, if you just stop" (King, 1991, p. 276).

Strong students might be able to see that Shooter's removed position can be understood as a theatrical implication that some hidden secret has re-emerged from Mort's unconscious and now occupies the young man's mind to the extent that "intense imagery vividness" (Reuber, forthcoming) provokes an increase in fear of annihilation. Mort's excruciating scream illustrates his own fear and sensation of ego liquidation, which is also supported by the juice of the blood oranges dripping down the board and smearing Mort's name to the degree that it becomes unrecognizable. The splattering orange might even be understood as the emblem of "Mort's head being knocked against the blackboard until it bursts open with a rotten squashing sound, and splatters gore and crimson across Mort's name, which after his death would be the only remaining attestation of his earthly existence" (Reuber, forthcoming).

Since the students will have analyzed this third dream at home, the teacher should enter the process of dream-interpretation only to "either nudge the learner along or remediate when needed" (Primeaux, 2000, p. 537). Students must be given the chance to develop reading, decoding, and analyzing skills not only through instruction, but also through individual interaction with the material, and with fellow students in the class without the teacher's constant interference. As Avril Haworth, Christopher Turner, and Margaret Whiteley (2004, p. 67) point out in their recently published book on Secondary English and Literacy, "reading is a social activity, involving the testing of interpretations through sharing them with others." Only through an open sharing of ideas and interpretations will the student obtain full insight in and understanding of the material and enhance his/her listening, presenting, analyzing, and interpersonal skills. Contrary to Jerry Farber's opinion (2007/08, p. 222) expressed in his article "Teaching and Presence," I believe that an in-class discussion is a very valuable teaching tool that guarantees the full "presence on the part of the students [and] the teacher." Listening to the individual presentations of how to analyze Mort's highly condensed third dream requires the teacher's utmost attention, since (s)he has to make sure that all important dream elements have been addressed. I suggest listing the individual dream thoughts and their latent content on the board and to complementing this list if necessary (see Chart 10). 


\begin{tabular}{|c|c|c|}
\hline Dream Thoughts & Dream Work & Dream Content \\
\hline $\begin{array}{l}\text { orange } \\
\text { splattering orange }\end{array}$ & & $\begin{array}{l}\text { fruit of the fall } \\
\text { symbol of fertility } \\
\text { harvest = ripe desire to kill his wife } \\
\text { weapon } \\
\text { threat } \rightarrow \text { ego-liquidation / murder }\end{array}$ \\
\hline orange colour & $\begin{array}{l}\text { projection / externalization of extreme } \\
\text { emotions }\end{array}$ & heated passion \\
\hline grocery bag & $\begin{array}{l}\text { condensation } \\
\text { composite structure }\end{array}$ & harvested desire to kill \\
\hline School of Hard Knocks & $\begin{array}{l}\text { displacement } \\
\text { composite structure }\end{array}$ & manifestation of Mort's unconscious \\
\hline John Shooter & $\begin{array}{l}\text { double figure } \\
\text { regression }\end{array}$ & $\begin{array}{l}\text { other vs. self } \\
\text { personification of Mort's primitive and } \\
\text { passionate longings }\end{array}$ \\
\hline Mort Rainey the writer & configuration & the gardener $\rightarrow$ "sowing season" \\
\hline
\end{tabular}

Chart 10: Board Comments - What is the Meaning of these Individual Dream Thoughts?

This brief listing of dream thoughts and their content illustrates the uncanny reoccurring over-determination of the dream content. Hence, the students will comprehend that the dream content "is not derived from a single element in the dream thoughts, but may be traced back to a whole number" (Freud, 1901, p. 32). They will realize that, on the one hand, this dream has a story of its own. On the other, it is connected to the dream in the cornfield by the here dominating image of the orange.

As the symbolic representation of fertility and a fruit of the fall, the orange refers back to the "huge secret garden" as well as the cornfield after harvest. Consequently, the orange functions as a composite structure of the two previous dream thoughts - the secret garden and the cornfield - that has been displaced into the (un)familiar classroom. Since the orange becomes a weapon in this third dream, it also reflects Mort's previously experienced fear of ego-liquidation provoked by "the knives, glittering in the hot sun" (King, 1991, p.255), further stressed by the image of blood sweating "its way onto the orange" (King, 1991, p. 276). The reddish colour of the "pinprick droplets" and the orange colour of the fruit's skin also suggest the dreamer's intense emotional state, which is supported by his loud shouts, "No more! No more! Please! I admit it, I'll admit anything!" (King, 1991, p. 276). But what is there to admit? It is interesting to ask the students what they think Shooter holds in his grocery bag, another (un)familiar and condensed dream image that refers back to the previously mentioned secret garden, in which Rainey's "forbidden fruit" can grow.

Last but not least the students should comment on the dream's location, "the school of Hard Knocks" (King, 1991, p. 275), a further dream manifestation of Mort's unconscious illustrating the phenomenon of displacement. Mort's desires, hopes, and fears are all kept within the walls of this (un)familiar school, a place that "educates" Mort about his repressed but most intense emotions: loyalty versus disloyalty, life versus death, Mort versus Shooter, that is ego versus Id, or self versus the other (the double). It is important that the students understand that due to the dream work, the common elements of the dream thoughts presented in a dream stand out in the form of condensed and composite structures, which in this particular dream are the (un)familiar school, the orange, and John Shooter. It is due to the process of condensation, compression, symbolization, and displacement that Mort Rainey seems to be "unable to discover or recognize the dream thoughts in the dream content" (Freud, 1901: 39), hence, to answer the simple question: "What kind of writer are you?" (King, 1991, p. 275).

In case students do not elaborate on Shooter's questions, "What's the matter? [...] What kind of writer are you? "(King, 1991, p. 275), the teacher should use this oversight and ask the class for the implicit meaning of this essential question. If the students have difficulties answering this question, the teacher should rephrase and ask: "What kind of gardener are you?" A comparison of the two questions and their significance in relation to the overall latent dream content serves as transition to this class's most important while-reading group activity: the indirect characterization of John Shooter and Mort Rainey via a description of their state of mind. 
Instead of asking the students to outline a conventional characterization of the two men, the teacher should choose a more technological approach of answering machine messages. Since the telephone plays a dominant role in the film, students outline the character's state of mind through an answering machine message Mort leaves for Amy, and one John Shooter leaves for Mort. In their messages, students have to be explicit but brief, emotional but also clear-minded, imaginary but also reality based, emotional but also calm. This group exercise advances the student's understanding, first of the individual character's drives, desires, anxieties, and thoughts; second, of the fear inspiring situation in general, and third, of the situation's effect on the character's language, diction, tone, and intonation. No homework is assigned.

\section{Part Five: Meeting the Double - The (Re)turn to the (Un)familiar}

In the last class of this unit, the focus shifts from Mort's nocturnal to his diurnal life; a life that by now is completely ruled by his unconscious. At the beginning of this class, students present their indirect characterizations of John Shooter and Mort Rainey via telephone messages. Rather than reading the imagined message aloud, each group chooses one designated "caller" who leaves Mort Rainey's and John Shooter's message on an answering machine provided by the teacher. After both messages have been recorded, they should be presented to the class and discussed. At the end of this exercise, students will have felt, realized, and learned that

- $\quad$ Mort is afraid, lost, helpless, lonely, depressed, and loosing his mind.

- Mort clings to his matrimonial past.

- $\quad$ Mort is accused of plagiarism provoking his guilty conscience.

- John Shooter imposes as much of a threat onto Mort Rainey as Ted Milner, Amy's new boyfriend.

- John Shooter personifies Mort's imaginary double, his guilty conscience of having committed plagiarism against John Kintner.

- John Shooter is Mort Rainey's personified desire to write the end of the story, which demands Amy's death.

This unconventional characterization of the two characters is not only a fun interactive activity, but also serves as a means of assessment for the teacher as it reflects well the student's understanding of the characters and their role in the film. The viewing of scenes twenty-five and twenty-six (01:15:12 - 01:25:15), scenes that reveal once more David Koepp's own translation of Stephen King's highly pictographic script, should follow this activity. The screening is essential as it brings our unit full circle.

In scenes twenty-five, twenty-six, and twenty-seven David Koepp illustrates very well Mort Rainey's mental and emotional confusion through flashbacks, hallucinations, interior monologues, and reappearing mirror images showing the amalgamation of the other (the double) and the self. By wearing the black hat, conversing with himself, imagining his living room split into half, and seeing the reflection of John Shooter in the mirror even though he is alone in the house, David Koepp addresses once and for all Mort Rainey's suffering from selfalienation, derealisation, and dissociation.

By letting John Shooter appear on top of the staircase connecting Mort Rainey's upper-level office with his lower-level living room, Koepp also visualizes Freud's defined entities of Id and ego, of unconscious and consciousness. It is on top of this liminal space that John Shooter steps out into the open and leaves Mort's office, the place where dangerous desires were processed, formulated, and put on paper, the place where John Shooter "was born."

Even though these scenes do not hold any dream sequence and, thus, are not subject to dream analysis, their highly symbolic content is essential for this unit and for the understanding of Mort Rainey's psyche. Students will understand that the office is the architectural manifestation of Mort's unconscious, out of which come shadowy behaviours and figures that are too difficult to understand. It is the writer's "secret garden." The fact that Mort's office is located on the top floor, directly under the house's roof, secluded from the outside world, is also important in the sense that its location reflects the inverted psychological powers of Mort's psyche: His unconscious dominates his consciousness; Mort's Id dominates his ego; Mort's common sense and values have given in to his instincts, passions, and desires. Understanding the summer cabin as a manifestation of Mort's mind as a whole, John Shooter 
then becomes the epitome of everything that the writer has ever imagined in his office, the small room that is connected to the outside world only via a secret window. I recommend the following stimulus as while-screening activity: "How does David Koepp visualize Mort's mental and emotional confusion, as well as the existence of the three Freudian entities, the ego, the super-ego, and the Id?"

Taking notes while watching the selected scenes is important for the subsequent analysis of the film sequence. To guarantee that students pay attention to all characteristics that are important for the elaboration of this complex question, the teacher should first divide the class into three groups, then hand out three different charts: Chart 11 focusing on the setting; Chart 12 directing its main interest on the cinematic effects; Chart 13 concentrating on the indirect characterization of Mort Rainey (see Charts 11, 12, and 13).

\begin{tabular}{|l|l|l|}
\hline SETTING (Scenes 25-27) & Example & Explanation \\
\hline details of setting & & \\
\hline effects of the characters & & \\
\hline $\begin{array}{l}\text { David Koepp's realization } \\
\text { (shots/colours/camera movement) }\end{array}$ & & \\
\hline
\end{tabular}

Chart 11: Representation of the Settings in Scenes 25-27

\begin{tabular}{|l|l|l|}
\hline CINEMATIC EFFECTS (Scenes 25-27) & Example & Explanation \\
\hline lightening & & \\
\hline colours & & \\
\hline $\begin{array}{l}\text { shots (long shot; medium shot; close-up; } \\
\text { extreme close-up) }\end{array}$ & & \\
\hline angle (low, eye-level, bird's-eye & & \\
\hline music/sound & & \\
\hline
\end{tabular}

Chart 12: Cinematic Effects in the Scenes 25-27

\begin{tabular}{|l|l|l|}
\hline $\begin{array}{l}\text { INDIRECT CHARACTERIZATION of } \\
\text { Mort Rainey (Scenes 25-27) }\end{array}$ & Example & Explanation \\
\hline actions / behaviour & & \\
\hline looks & & \\
\hline speech & & \\
\hline dress & & \\
\hline effect on others & & \\
\hline
\end{tabular}

Chart 13: Indirect Characterization of Mort Rainey Scenes 25-27

After the screening it is important to give the students enough time to complement their individual findings through in-group discussion, before sharing examples and their interpretation with the rest of the class. Since the main interest is in how David Koepp visualizes Mort's mental and emotional confusion, the first group to present their interpretation to the class should be the one who worked on Chart 4. This particular group will elaborate on Johnny Depp's theatrically and David Koepp's cinematographic portrayal of Mort Rainey's split personality manifesting itself in his verbalized stream of consciousness, self-questioning, self-alienation, and his dissolving and John Shooter's reappearing mirror image on the summer cabin's upper staircase, the place where Mort Rainey awaits later the arrival of his ex-wife.

The discussion of David Koepp's cinematic effects should follow the indirect characterization of Mort Rainey, since Koepp's decision on how to combine the character's behaviour, monologue, and artificial dialogue with lighting, camera angle, sound effects, and music mimics "the thoughts and feelings that occur in [Mort Rainey's] stream of consciousness" (Wedding, ${ }^{2} 2001$, p. 5). This way, students will be able to put Mort Rainey's conduct disorder, separation anxiety, and nostalgia for his marital life in context with Koepp's cinematic decision, as for example his choice of low-key and high-contrast lighting when having flashbacks of his past deeds. The contrasts of light and dark as well as the often used symbol of the mirror support the psychological understanding of 
the character's mind, which is haunted by the recurring repressed past that finds personification in John Shooter, Mort's (un)familiar double. Hence, "the disparity of dark and light" (Cahir, 2006, p. 67) is crucial to the understanding of Mort's psyche, but should not be mistaken for any racial comment.

In addition to lighting, Koepp's alteration between frequent medium and extreme close-up shots of Mort Rainey - especially when he stares into the mirror - as well as the director's high, oblique, and eye-level camera angles on the character should be discussed as important means of indirect characterization. The fact that the camera zooms in on Mort when putting on the black hat and when standing in front of the mirror underlines the intensity and subjectivity of this particular scene and lets us - the viewer-discover Mort's major source of fear and threat through his own eyes: John Shooter alias Mort's uncontrollable desire to kill his ex-wife; a desire that has reoccurred every now and then in the apparently "disconnected fragments of visual images" (Freud, 1901, p. 40) of his dreams and that has been expressed by John Shooter's demand "to fix the ending" of the story. At this point of the film, Mort's alter ego has left the dream world and is descending the staircase leading to Mort's office - the place where his imagination runs wild and from which "something long known to [him], once very familiar" (Freud, 1919, p. 370) now returns: his sensation of betrayal by his ex-wife Amy.

The third group, presenting their elaborations on the setting, will set Mort's confusion and mental disorder in relation to the disorder in the house already apparent in scene eight, the second film segment discussed in class. Broken dishes, dirty plates, and damaged furniture, as well as ripped paper and journals, symbolically illustrate the young man's collapsed marital and professional life as well as his psychic imbalance. This last group, thus, shows how Mort's external reality is a reflection of his internal psychic one.

\section{CONCLUSION}

With a detailed elaboration of these individual components of the film and their symbolic reading, this unit comes to an end. Students will be able to contrast their first reading of the DVD, to understand and use a classical Freudian approach to text and film, to judge David Koepp's cinematographic realization of King's text, and to comprehend John Shooter as Mort's surrounding darkness - his hideous double - that is so domineering on the DVD cover. Students will have acquired the competence to explain why "some windows should never be opened" (DVD cover) and to set this statement in relation to Freud's understanding of a dream as a disguised fulfilment of a wish.

In addition to being able to approach a text and film from a psychoanalytical point of view and to understand the similarities between dream, text, and film analysis, students will also have learned about the tremendous change the Gothic genre has undergone in the twentieth century. Even though King's fiction evokes the typical Gothic themes of good versus evil, the villain's quest for the forbidden, seemingly supernatural components evoking strangeness, the opposing entities of self and other in solitary confinement, and thus the figure of the double, Secret Window distinguishes itself from its generic predecessors. Horace Walpole's and Anne Radcliffe's supernatural manifestations of the (outer) uncanny have been exchanged for representations of a more psychological (inner) uncanny. Giant helmets falling from the sky or eerie melodies coming out of the woods are no longer the focus. The illustration of man's darkest personal and "darkest collective cultural and social anxieties" in addition to the "collapse of social [individual, and family] values" (Magistrale, 2007, pp. 64; 63) are at the center of this modern Gothic text. Walpole's Manfred and Radcliff's Montoni have been replaced by King's mad writer developing into a "two-faced serial killer" (Strengell, 2005, p. 69) in order to obtain his inner peace.

Secret Window thus shows a combination of the old (gothic tropes and themes) and new that lets the characters and readers discover, or rather return, to that particular fear of the (un)familiar unknown of the enclosed space that once found its symbolic manifestation in the Gothic castle, but that now has chosen a more psychological setting: the human mind; a place that holds all of our anxieties, fears, desires, and instincts; a place that keeps and releases our most intense emotional or mental pain provoked by the development, or should I rather say, the reoccurrence of the (true) self in relation to the other? It has developed into a place of duality; "namely, the paradoxical existence of both good and evil in a single person" (Strengell, 2005, p. 68) to which all of us can fall victim. 
For their final project, students should watch the entire film and then be given the opportunity to elaborate on this transformation of the Gothic genre and to compare Stephen King's Secret Window with other texts they will have read in the seminar; for example, Horace Walpole's The Castle of Otranto, Mathew Lewis's The Monk, Mary Shelley's Frankenstein, Edgar Allan Poe's "The Black Cat," or Richard Stevenson's Dr. Jekyll and Mr. Hyde. Dreams, hallucinations, and nightly terrors are essential components in all these works, but the manifestation of the uncanny has never inspired such a strong sensation of terror until the moment when Mort Rainey opened the secret window to his soul and mind.

\section{AUTHOR INFORMATION}

Alexandra Reuber, Ph.D. in Comparative Literature and M.A. in Teaching Foreign Languages, is a Professor of Practice of French and the Director of the French Language Program at Tulane University, Louisiana, USA. She teaches French literature, culture, and history, as well as seminars on gothic and fantastic literature, and New Orleans folklore. As an Adjunct Professor of Tulane's Teacher Preparation and Certification Program, she also teaches Method and Language Pedagogy courses.

\section{REFERENCES}

1. Albers, Peggy and Jerome C. Harste, The Arts, New Literacies, and Multimodality, English Education, Vol. 40, No.1, pp. 6-20, 2007.

2. Cahir Costanzo, Linda, Literature into Film, McFarland, Jefferson, NC and London, 2007.

3. Chacón, Carmen T, My Journey into Racial Awareness, Color, Race, and English Language Teaching. Shades of Meaning, edited by Andy Curtis and Mary Romney, Lawrence Erlbaum Associates, Mahwah, N. J., pp. 49-64, 2006.

4. $\quad$ Easthope, Antony, The Unconscious, Routledge, London and New York, 1999.

5. Farber, Jerry, Teaching and Presence, Pedagogy: Critical Approaches to Teaching Literature, Language, Composition, and Culture, Vol. 8, No. 2, pp. 215-225, 2007/08.

6. Foertsch, Jacqueline, Books as Broccoli? Images as Ice Cream? Providing a Healthy Menu in a College English Classroom, Pedagogy: Critical Approaches to Teaching Literature, Language, Composition, and Culture, Vol. 6, No. 2, pp. 209-230, 2006.

7. Freud, Sigmund (1900), The Interpretation of Dreams, translated by James Strachey, The Hogarth Press, London, 1995.

8. --- (1901), On Dreams, translated by James Strachey, The Standard Edition, W. W. Norton \& Company, New York, 1990.

9. $\quad$---.(1919), Papers on Applied Psychoanalysis. The Uncanny, Collected Papers Vol. 4, translated by Joan Riviere, The Hogarth Press, London, pp. 368-407, 1949.

10. ---(1923) The Ego and the Id, translated by Joan Riviere, edited by James Strachey, The Standard Edition, W.W. Norton \& Company, Inc., New York, 1989.

11. Golden, John, Literature into Film (and Back Again): Another Look at an Old Dog, English Journal, Vol. 97, No. 1, pp. 24-30, 2007.

12. --- Reading in the Dark. Using Film as a Tool in the English Classroom, National Council of Teachers of English Urbana, IL, 2001.

13. Haworth, Avril, Secondary English and Literacy. A Guide for Teachers, Paul Chapman Publishing, London, 2004.

14. King, Stephen, Secret Window, Secret Garden, Four Past Midnight, Penguin Books, Signet, London, pp. 235-382,1991.

15. Koepp, David, Secret Window, directed by David Koepp, performing Johnny Depp, John Turturro, and Maria Bello, DVD, Columbia Pictures, 2004.

16. Lebeau, Vicky, Psychoanalysis and Cinema. The Play of Shadows, Wallflower Press, London and New York, 2001.

17. MacAndrew, Elizabeth, The Gothic Tradition in Fiction Columbia, University Press, New York, 1979.

18. Magistrale, Tony, 2007. Tracing the Gothic Inheritance: Danse Macabre, Bloom's Modern Critical Views: Stephen King Updated Edition, edited by Harold Bloom, Chelsea House Publishers, New York, pp. 59-66, 2007. 
19. McKnight, Katherine and Bradley P. Berlage, Teaching the Classics in the Inclusive Classroom, JosseyBass, United States, 2008.

20. Primeaux, Joan, Focus on Research. Shifting Perspectives on Struggling Readers, Language Arts, Vol. 77, No. 6-7, pp. 537-542, 2000.

21. Reuber, Alexandra, King's Psychological Gothicism in Secret Window, Secret Garden: Repression, Illusion, and Parasomnia, or ... How well did you sleep?" King's New Millenium, edited by Mary Findley, Cambridge Scholars Publishing, forthcoming.

22. Revonsuo, Antti, The Self in Dreams, The Lost Self, edited by Todd E. Feinberg and Julian Paul Keenan, Oxford University Press, Oxford and New York, pp. 206-219, 2005.

23. Sage, Victor and Allan Lloyd Smith, Modern Gothic. A Reader, Manchester University Press, Manchester and New York, 1996.

24. Skretta, John, King's Works and the At-Risk Student, Reading Stephen King, edited by Brenda Miller Power, Jeffrey D. Wilhelm, and Kelly Chandler, National Council of Teachers of English, United States of America, pp. 127-138, 1997.

25. Strengell, Heidi, Dissecting Stephen King. From the Gothic to Literary Naturalism, The University of Wisconsin Press, Madison, WI, 2005.

26. Weaver, John A, Popular Culture, Peter Lang, New York, 2005.

27. Wedding, Danny and Mary Ann Boyd and Ryan M. Niemiec, Movies and Mental Illness. Using Films to Understand Psychopathology, Hogrefe \& Huber Publishers, Cambridge, MA, ${ }^{2} 2001$.

\section{NOTES}

Gothic Fiction is a regularly reappearing seminar within the corpus of classes of any English Department. Even though the course syllabus differs from one teacher to the other especially regarding the incorporation of modern gothic texts, teachers always select some of the most important classical works among which we find the following: Horace Walpole's The Castle of Otranto (1764), Anne Radcliffe's The Mysteries of Udolpho (1794) or The Italian (1797), Matthew Lewis' The Monk (1796), Mary Shelley's Frankenstein (1831), Edgar Allan Poe's "The Fall of the House of Usher" (1839) or "The Black Cat" (1843), Robert Louis Stevenson's The Strange Case of Dr. Jekyll and Mr. Hyde (1886), Bram Stoker's Dracula (1897), or even Oscar Wilde's The Picture of Dorian Gray (1890). This being said, we can assume that by the time students discuss Stephen King's contribution to the gothic genre they will be very well prepared to do so. They will have no difficulty to characterize the story's 'gothic villain,' to describe and read the modern gothic dwelling, to understand the phenomenon of persecution and paranoia, and to elaborate on the use of colors, shapes, eventual supernatural elements, and dark convoluted architectural structures.

2 Even though the black and white dichotomy is present in the poster and throughout the film, it would be wrong to understand the use of this dichotomy as a tool alluding to social inequities or even as implied racial tension. If at all, this dichotomy expresses the opposite. In contrast to many Hollywood depictions of the "rich White Americans who live in beautiful houses, own luxurious cars, and earn good salaries" (Chacón, 2006, p.53), here, the portrayal of the white and not of the black man is negative. Mort Rainey is professionally unsuccessful and reacts violently against his surroundings. He hosts something dark inside, something for which his white skin serves as camouflage. In this sense, it is Mort Rainey who is "other," the dark sheep among the "good" white people. In contrast to the "dark" Mort Rainey, the only black character in the film is Ken Karsch, a successful and level headed lawyer whose dark skin overshadows his good and helpful soul. As a matter of fact, it would be wrong to understand Secret Window as a story about racial injustice, divisiveness, or identity.

3 Since Gothic fiction appeals to our senses and fears, it can be assumed that teachers of the gothic also include the visual medium in their syllabi in order to round off the students' gothic experience with an understanding of the genre. Since the analysis of a Stephen King text or its cinematographic adaptation would be placed at the end of the seminar, it is very likely that by this time students have been exposed to other cinematic interpretations of gothic sources and are consequently familiar with film terminology and the reading of cinematic effects.

$4 \quad$ I intentionally propose Freud's On Dreams over using his ground-breaking work The Interpretation of Dreams (1900), as On Dreams offers a condensed and revised outline of his view on dream structure, dream language, and dream work. As such it is easier to include in course syllabi. 
5 David Koepp's cinematic realization of Secret Window is much closer than Stanley Kubrick's literal translation (1980) of King's bestseller The Shining (1977), or Mike Halfström's radical translation (2007)

David Koepp visualizes Mort Rainey's escape into the dream world throughout the film. The most predominant examples can be found in the following six scenes: Scene 1, scene 5, scene 8, scene 18, scene 19 , and scene 21 .

7 When working with selected scenes instead of the entire film, the teacher has to be aware of a possible risk: Some students might have already seen the movie in the theaters or at home. Depending on how well they still remember the film, they might have an advantage over the students who are unfamiliar with the movie. Since the film is already five years old and was not considered a "huge box-office hit," we should not expect too many students being familiar with the film. 
NOTES 